\title{
Functional Magnetic Resonance Imaging Before and After Ventriculoperitoneal Shunting for Hydrocephalus
}

\author{
-Case Report-
}

\author{
Toru FUKUhara, Mark G. LUCIANO, Jing Z. LIU*, and Guang H. YUE* \\ Departments of Neurological Surgery and *Biomedical Engineering and Rehabilitation Medicine, \\ The Cleveland Clinic Foundation, Cleveland, Ohio, U.S.A.
}

\begin{abstract}
A 70-year-old man with hydrocephalus was examined with functional magnetic resonance (fMR) imaging before and after ventriculoperitoneal shunting. Preoperatively, activation by right hand exercise revealed only a slight signal increase in the peri-rolandic area. However, 3 months after ventriculoperitoneal shunting, a significant signal increase was observed. fMR imaging may detect activity-related improvement of cerebral blood flow responses in patients with hydrocephalus after surgical treatment.
\end{abstract}

Key words: cerebral blood flow, functional magnetic resonance imaging, hydrocephalus, neural activation

\section{Introduction}

Functional magnetic resonance (fMR) imaging has rapidly become a useful technique in clinical practice. ${ }^{21)}$ fMR imaging was initially utilized to detect and localize normal brain function, ${ }^{22,29,32)}$ but has progressed with the introduction of high-speed MR imaging and the use of various stimulation tasks. ${ }^{23)}$ fMR imaging has been applied to determine the location of eloquent brain function as part of the preoperative evaluation for brain tumor resection ${ }^{8)}$ and epilepsy surgery. ${ }^{4)}$ Other recent fields of use include examination of the pathophysiology of such conditions as schizophrenia, ${ }^{33)}$ stroke, ${ }^{3)}$ and anosmia, ${ }^{15)}$ by comparing the images of patients with the disease to normal controls. This study used pre- and postoperative fMR imaging in a patient with hydrocephalus to document the apparent differences related to shunting.

\section{Case Report}

A 70-year-old male presented with progressive gait disturbance persisting for approximately 2 years. The patient's family thought his gait had become worse over the previous 6 months and also reported urinary incontinence and decreased short-term memory. He was referred to our institution for evaluation of suspected normal pressure hydrocephalus. His medical history included longstanding essential hypertension and diet-controlled diabetes mellitus, and an incident of subarachnoid hemorrhage 18 years before, which was treated conservatively because of unknown origin despite repeated cerebral angiography.

Neurological examination showed mild dementia and markedly ataxic gait. He also exhibited right hand tremor, exaggerated during intentional movement. MR imaging of the brain revealed enlarged ventricles and widening of the cortical sulci. A lumbar spinal tap for examination of cerebrospinal fluid (CSF) was performed. The opening pressure was $22.4 \mathrm{cmH}_{2} \mathrm{O}$, and $30 \mathrm{~cm}^{3}$ of clear $\mathrm{CSF}$ was withdrawn. CSF examination found no signs of infection or abnormal chemistry. Following CSF withdrawal, the patient's gait clearly improved, but only transiently for a few days, which indicated that he might benefit from CSF diversion. A component of degenerative disease could not be ruled out definitively.

Received April 17, 2001; Accepted September 27, 2001

Author's present address: T. Fukuhara, M.D., Department of Neurological Surgery, Okayama University Medical School, Okayama, Japan. 
fMR imaging was performed on a SIEMENS $1.5 \mathrm{~T}$ VISION system (Siemens, Erlangen, Bayern, Germany). Twenty contiguous axial brain slices of $6 \mathrm{~mm}$ thickness were imaged with an interleaved multislice gradient-echo, echo-planar pulse sequence (repetition time/echo time/flip angle $=500 \mathrm{msec} /$ $30 \mathrm{msec} / 45$ degrees). The field of view was $256 \times$ $256 \mathrm{~mm}$ and the matrix size was $128 \times 128$, yielding a spatial resolution of $2.0 \mathrm{~mm} \times 2.0 \mathrm{~mm}$. Closing and opening the right hand (once/2 sec) was employed as the motor activity task. The patient was told to apply moderate grip force when closing the hand. The investigator checked the level of grip force by asking the patient to squeeze his hand. After allowing approximately 5 minutes training of the hand exercise, the experiment was begun. The hand exercise was performed in an "OFF-ON-OFF-ONOFF" manner with "OFF" representing the baseline (rest) condition and "ON" the task condition. Each "ON" or "OFF" period lasted 18 seconds and the exercise started 2 seconds before the first "ON" period began. Six images were acquired for each slice during each "ON" or "OFF" period. This allowed image averaging to improve the signal-to-noise ratio. Postimage processing and analysis were performed with a MEDX software package (MEDX 2.1; Sensor Systems, Inc., Sterling, Va., U.S.A.), specifically designed for functional imaging analysis. The first image of each slice in each "ON" or "OFF" period was excluded during post-image processing to allow similar $\mathrm{T}_{1}$ weighting of all the images. Images acquired during the "ON" periods were compared to the images obtained during the "OFF" periods on a pixel-by-pixel basis. The Student's t-test was used for comparisons. Pixels with a z score of 2.5 or higher at a 0.05 level of statistical significance were included in the functional map. However, significantly activated pixels with less than five contiguous neighbors were not included. The functional map was laid over a $\mathrm{T}_{1}$-weighted anatomical image to determine the locations of activation. Minimal activation was observed in the left peri-rolandic cortex before the surgical treatment (Fig. 1).

Right occipital ventriculoperitoneal (VP) shunting, using a pressure-programmable valve (Johnson \& Johnson, Lelocle, Switzerland) set at $120 \mathrm{mmH}_{2} \mathrm{O}$, was performed under the diagnosis of communicating hydrocephalus. The patient's gait and urinary incontinence improved markedly following shunting, leaving only residual decreased short-term memory. Right hand tremor also decreased, but persisted with mild intentional component. These clinical findings were confirmed at 6-week follow up, although the ventricular size remained almost unchanged on computed tomography (Fig. 2). fMR imaging was repeated 3 months after the shunt procedure. Special attention was paid to maintain the same number of hand movements and similar grip force of each hand-closing contraction as used in the hand exercise performed during the first fMR imaging experiment. An obvious increase of activation in the perirolandic cortex was observed (Fig. 3). The patient was stable at 1-year follow up, and clinically unchanged since the first postoperative visit.

\section{Discussion}

Hydrocephalus is one of the most common diseases treated by neurosurgeons, but the exact pathophysiological changes underlying observed clinical improvement is not fully understood. Whether a CSF diversion procedure will improve symptoms is often difficult to predict, especially for patients with chronic hydrocephalus. In our institution, a 3-day continuous lumbar CSF drainage is performed to evaluate the indications for VP shunt. In the present patient, the slightly high CSF pressure and the clear clinical improvement seen after removal of $30-\mathrm{cm}^{3}$ CSF indicated VP shunting without further procedures. The clinical changes after shunting do not correlate well with ventricular size, especially in cases of chronic hydrocephalus. Frequently clinical improvement is seen without significant changes in ventricular size.6,16)

The improvement of cerebral blood flow (CBF) after VP shunting has been frequently discussed as a potent mechanism of symptom improvement. ${ }^{25,30}$ ) However, CBF improvement alone does not necessarily lead to the symptomatic resolution. ${ }^{18,30}$ ) Cerebral metabolism studies with positron emission tomography of glucose utilization ${ }^{10,13,27,31)}$ and oxygen utilization ${ }^{2)}$ have also revealed that reduction of periventricular metabolism is a common finding in untreated hydrocephalus. However, postoperative increases in metabolism are not always seen despite clinical improvement. ${ }^{2,10}$ ) Such changes in CBF or neuronal metabolism in the resting condition are inconsistent with the observed clinical improvements after treatment of hydrocephalus. Dysfunction of white matter including fiber stretchings) or decreased connectivity ${ }^{19)}$ are also likely to be involved, so no single mechanism can explain the symptoms of hydrocephalus.

Dysfunction of vessel reactivity to stimulation (autoregulation) may be one of the mechanisms responsible for the symptoms of hydrocephalus. Loss of chemical autoregulation, the vessel response to blood $\mathrm{CO}_{2}$ changes, may have been involved ${ }^{20)}$ and may be predictive of clinical outcome after VP shunt placement. ${ }^{14,26)}$ This mechanism was recently exam- 


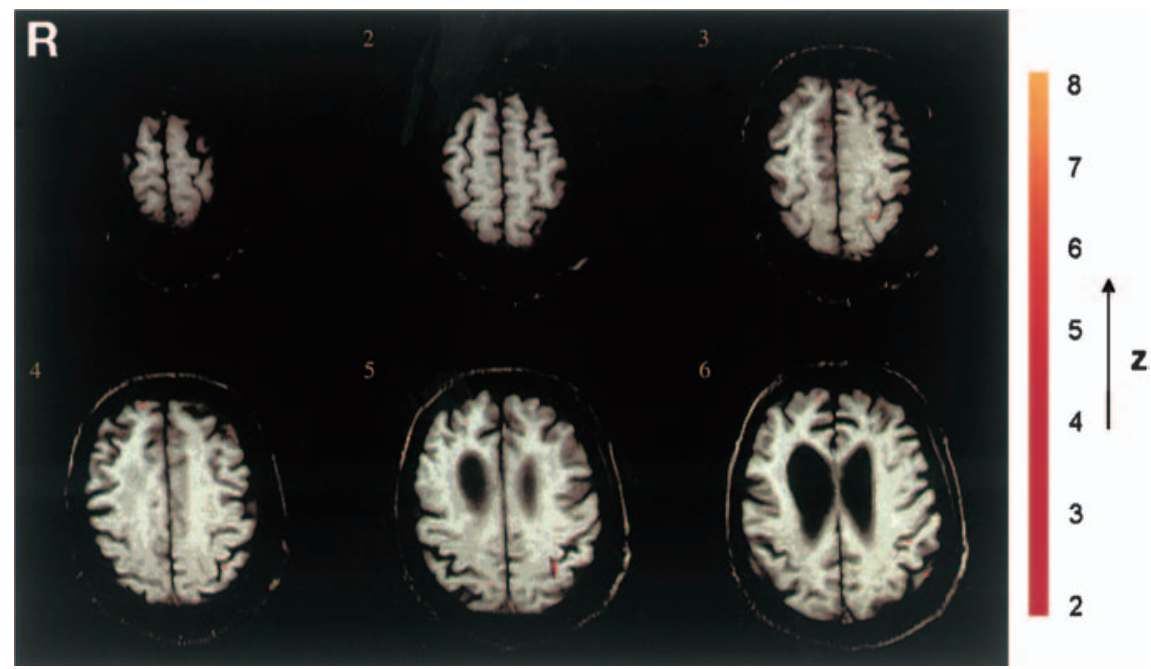

Fig. 1 Preoperative functional magnetic resonance images showing a subtle signal increase in the left peri-rolandic cortex with right hand exercise.

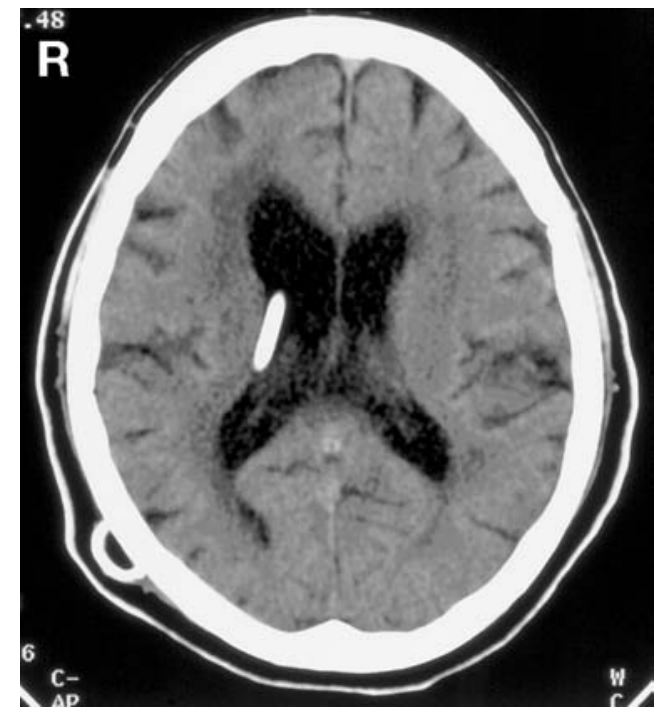

Fig. 2 Postoperative head computed tomography scan 6 weeks after a right occipital horn ventricular catheter was placed for ventriculoperitoneal shunting. The ventricular size has not changed in spite of clinical improvement.

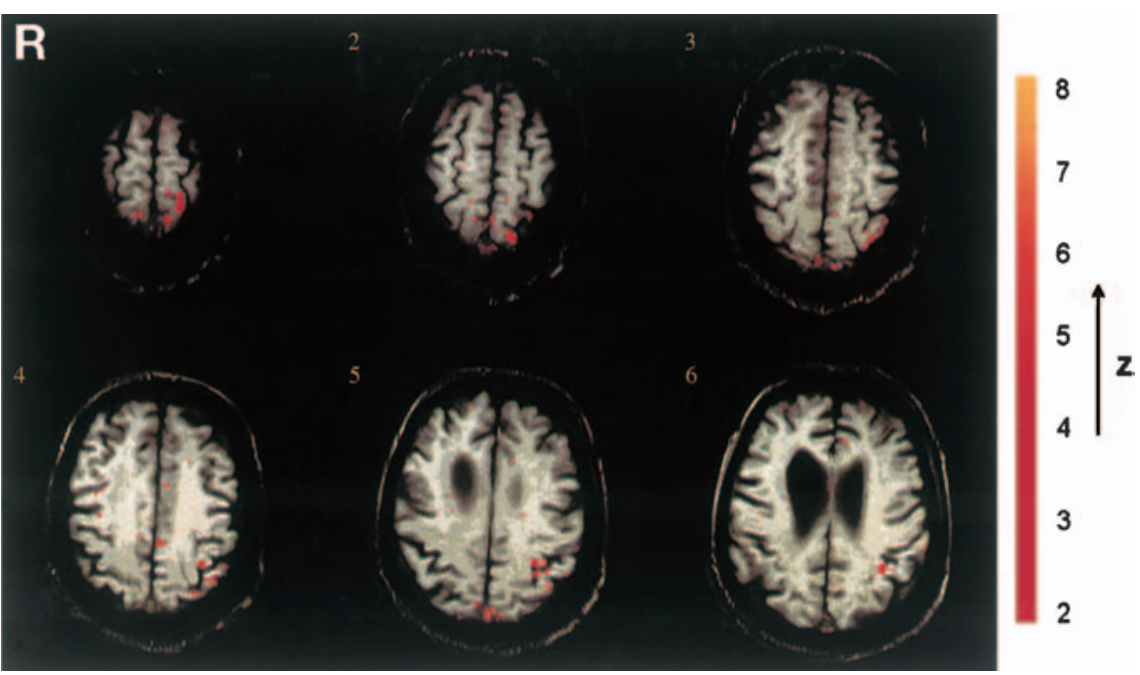

Fig. 3 Functional magnetic resonance images 3 months after ventriculoperitoneal shunting showing a significant signal increase in the left perirolandic cortex with right hand exercise. 
ined in our chronic hydrocephalus model. ${ }^{9)}$ Activityinduced CBF increase can be considered as another type of autoregulation. fMR imaging performed during motor tasks reveals the responsiveness of the brain to the activation. ${ }^{23)}$ fMR imaging changes may correlate with clinical improvement more closely than imaging of the resting neuronal function. fMR imaging detects the uncoupling of CBF and oxidative metabolism during activation. The increase in CBF is proportionally greater than the increase in metabolism during task/stimulus activation. ${ }^{7,24)}$ The excess increase of CBF translates into a regional increase of oxyhemoglobin, despite the increased production of deoxyhemoglobin due to activated cells. ${ }^{17)}$ Therefore, fMR imaging reveals the activitydependent CBF responses, and not the metabolism response. The mechanisms coupling neuronal activation to increased CBF are still unclear. However, nitric oxide, ${ }^{1)}$ astrocyte-derived epoxyeicosatrienoic acids, ${ }^{12)}$ or the chorinergic system ${ }^{28)}$ may be involved.

This study found significant changes in fMR imaging findings following VP shunting for hydrocephalus that correlated well with the clinical improvement. A comparable fMR imaging study noted no changes before and after cocaine infusion with visual stimulation. ${ }^{11)}$ Further fMR imaging studies of patients with hydrocephalus are required to better understand the extent of regional deficits in brain activation and recovery after treatment.

\section{Acknowledgment}

This study was supported in part by a grant from National Institute of Neurological Disorders and Stroke (NS35130).

\section{References}

1) Akgoren N, Dalgaard P, Lauritzen M: Cerebral blood flow increases evoked by electrical stimulation of rat cerebellar cortex: relation to excitatory synaptic activity and nitric oxide synthesis. Brain Res 710: 204-214, 1996

2) Brooks DJ, Beaney RP, Powell M, Leenders KL, Crockard HA, Thomas DGT, Marshall J, Jones T: Studies on cerebral oxygen metabolism, blood flow, and blood volume, in patients with hydrocephalus before and after surgical decompression, using positron emission tomography. Brain 109: 613-628, 1986

3) Cramer SC, Nelles G, Benson RR, Kaplan JD, Parker RA, Kwong KK, Kennedy DN, Finklestein SP, Rosen BR: A functional MRI study of subjects recovered from hemiparetic stroke. Stroke 28: 2518-2527, 1997

4) Desmond JE, Sum JM, Wagner AD, Demb JB, Shear
PK, Glover GH, Gabrieli JD, Morrell MJ: Functional MRI measurement of language lateralization in Wada-tested patients. Brain 118: 1411-1419, 1995

5) Fisher CM: Hydrocephalus as a cause of disturbances of gait in elderly. Neurology 32: 1358-1363, 1982

6) Foltz EL, Blanks J, Meyer R: Shunted hydrocephalus: normal upright ICP by CSF gravity-flow control. A clinical study in young adults. Surg Neurol 39: 210-217, 1993

7) Fox PT, Raichle ME: Focal physiological uncoupling of cerebral blood flow and oxidative metabolism during somatosensory stimulation in human subjects. Proc Natl Acad Sci U S A 83: 1140-1144, 1986

8) Fried I, Nenov VI, Ojemann SG, Woods RP: Functional MR and PET imaging of rolandic and visual cortices for neurosurgical planning. J Neurosurg 83: 854-861, 1995

9) Fukuhara $\mathrm{T}$, Luciano MG, Brant CL, Klauscie J: Effects of ventriculoperitoneal shunt removal on cerebral oxygenation and brain compliance in chronic obstructive hydrocephalus. J Neurosurg 94: 573-581, 2001

10) George AE, De Leon MJ, Miller J, Klinger A, Foo SH, Christman DL, Wolf A: Positron emission tomography of hydrocephalus. Metabolic effects of shunt procedures. Acta Radiol Suppl 369: 435-439, 1986

11) Gollub RL, Breiter HC, Kantor H, Kennedy D, Gastfriend D, Mathew RT, Makris N, Guimaraes A, Riorden J, Campbell T, Foley M, Hyman SE, Rosen B, Weisskoff R: Cocaine decreases cortical cerebral blood flow but does not obscure regional activation in functional magnetic resonance imaging in human subjects. J Cereb Blood Flow Metab 18: 724-734, 1998

12) Harder DR, Alkayed NJ, Lange AR, Gebremedhin D, Roman RJ: Functional hyperemia in the brain: hypothesis for astrocyte-derived vasodilator metabolites. Stroke 28: 229-234, 1998

13) Kaye JA, Grady CL, Haxby JV, Moore A, Friedland RP: Plasticity in the aging brain. Reversibility of anatomic, metabolic, and cognitive deficits in normalpressure hydrocephalus following shunt surgery. Arch Neurol 47: 1336-1341, 1990

14) Klinge PM, Berding G, Brinker T, Knapp WH, Samii M: A positron emission tomography study of cerebrovascular reserve before and after shunt surgery in patients with idiopathic chronic hydrocephalus. J Neurosurg 91: 605-609, 1999

15) Levy LM, Henkin RI, Hutter A, Lin CS, Schellinger D: Mapping brain activation to odorants in patients with smell loss by functional MRI. J Comput Assist Tomogr 22: 96-103, 1998

16) Mabe H, Suzuki K, Nagai H: Cerebral blood flow after ventriculoperitoneal shunt in children with hydrocephalus. Childs Nerv Syst 6: 388-391, 1990

17) Malonek D, Dirnagl U, Lindauer U, Yamada K, Kanno I: Vascular imprints of neuronal activity: Relationships between the dynamics of cortical blood flow, oxygenation, and volume changes following 
sensory stimulation. Proc Natl Acad Sci U S A 94: 14826-14831, 1997

18) Mamo HL, Meric PC, Ponsin JC, Rey AC, Luft AG, Seylaz JA: Cerebral blood flow in normal pressure hydrocephalus. Stroke 18: 1074-1080, 1987

19) McAllister JP II, Chovan P: Neonatal hydrocephalus. Mechanisms and consequences. Neurosurg Clin North Am 9: 73-93, 1998

20) Meyer JS, Tachibana H, Hardenberg JP, Dowell RE Jr, Kitagawa Y, Mortel KF: Normal pressure hydrocephalus. Influences on cerebral hemodynamic and cerebrospinal fluid pressure-chemical autoregulation. Surg Neurol 21: 195-203, 1984

21) Moseley ME, deCrespigny A, Spielman DM: Magnetic resonance imaging of human brain function. Surg Neurol 45: 385-391, 1996

22) Ogawa S, Tank DW, Menon R, Ellermann JM, Kim SG, Merkle H, Ugurbil K: Intrinsic signal changes accompanying sensory stimulation: functional brain mapping with magnetic resonance imaging. Proc Natl Acad Sci U S A 89: 5951-5955, 1992

23) Rosen BR, Buckner RL, Dale AM: Event-related functional MRI: Past, present, and future. Proc Natl Acad Sci U S A 95: 773-780, 1998

24) Sappey-Marinier D, Calabrese G, Fein G, Hugg JW, Biggins C, Weiner MW: Effect of photic stimulation on human visual cortex lactate and phosphates using ${ }^{1} \mathrm{H}$ and ${ }^{31} \mathrm{P}$ magnetic resonance spectroscopy. J Cereb Blood Flow Metab 12: 584-592, 1992

25) Tamaki N, Kusunoki T, Wakabayashi T, Matsumoto S: Cerebral hemodynamics in normal-pressure hydrocephalus. Evaluation by ${ }^{133} \mathrm{Xe}$ inhalation method and dynamic CT study. J Neurosurg 61: 510-514, 1984

26) Tanaka A, Kimura M, Nakayama Y, Yoshinaga S, Tomonaga M: Cerebral blood flow and autoregulation in normal pressure hydrocephalus. Neurosurgery 40: 1161-1167, 1997

27) Tedeschi E, Hasselbalch SG, Waldemar G, Juhler M,
Høgh P, Holm S, Garde L, Knudsen LL, Klinken L, Gjerris F, Paulson OB: Heterogeneous cerebral glucose metabolism in normal pressure hydrocephalus. $J$ Neurol Neurosurg Psychiatry 59: 608-615, 1995

28) Tsukada H, Kakiuchi T, Ando I, Shizuno H, Nakanishi S, Ouchi Y: Regulation of cerebral blood flow response to somatosensory stimulation through the chorinergic system: a positron emission tomography study in unanesthetized monkeys. Brain Res 749: 10-17, 1997

29) Vitte E, Derosier C, Caritu Y, Berthoz A, Hasboun D, Soulie D: Activation of the hippocampal formation by vestibular stimulation: a functional magnetic resonance imaging study. Exp Brain Res 112: 523-526, 1996

30) Vorstrup S, Christensen J, Gjerris F, Sørensen PS, Thomsen AM, Paulson OB: Cerebral blood flow in patients with normal-pressure hydrocephalus before and after shunting. J Neurosurg 66: 379-387, 1987

31) Wong CO, Luciano MG, MacIntyre WJ, Brunken RC, Harn JF, Go RT: Viable neurons with luxury perfusion in hydrocephalus. J Nucl Med 38: 1467-1470, 1997

32) Yetkin FZ, Mueller WM, Hammeke TA, Morris GL III, Haughton VM: Functional magnetic resonance imaging mapping of the sensorimotor cortex with tactile stimulation. Neurosurgery 36: 921-925, 1995

33) Yurgelun-Todd DA, Waternaux CM, Choen BM, Gruber SA, English CD, Renshaw PF: Functional magnetic resonance imaging of schizophrenic patients and comparison subjects during word production. Am J Psychiatry 153: 200-205, 1996

Address reprint requests to: T. Fukuhara, M.D., Department of Neurological Surgery, Okayama University Medical School, 2-5-1 Shikata-cho, Okayama 700-8558, Japan. 